\title{
Argon Laser Micro-irradiation of Mitochondria in Rat Myocardial Cells in Tissue Culture
}

\section{Correlation of Morphology and Function in Irradiated Single Cells}

\author{
MICHAET, W. BERNS, DEBORAH C. L. GROSS, WANNY K. CHENG \\ AND DOUGLAS WOODRING
}

Department of Zoology, The University of Michigan, Ann Arbor, Mich. 48104, U.S.A.

(Received 20 August 1971, and accepted 1 October 1971)

\begin{abstract}
M. W. Berns, D. C. L. Gross, W. K. Chen and D. Woodring. Argon Laser Microirradiation of Mitoohondria in Rat Myocardial Cells in Tissue Culture. II. Correlation of Morphology and Function in Irradiated Single Cells. Journal of Molecular and Cellular Cardiology (1972) 4, 71-83. It has been established that mitochondrial lesions of specific severity and morphology could be produced in myocerdial cells by laser microbeam irrediation. This paper (i) describes four general categories of contractility responses resulting from irradiation of a single mitochondrion in a beating myocardial cell (group I, no change; group II, change followed by return to rhythmic contractions; group III, cessation of contraction; group IV, cell death); (ii) correlates mitochondrial lesion type with functionsl response; and (iii) distinguishes between physiologiosl deprivation of mitoohondria within the coll and secondary effects due to laser energy dissipation. Of the 22 contracting cells that were altered but did not die (groups II and III) 18 returned to rhythmic contractility statistically similar to the pre-irradiation contraction rate. A definite correlation between lesion severity and functional response was noted : only cells in Group I (no change) had the least severe lesion type (8/14), and none had the most severe lesion type. Twenty of 22 cells in groups II and III had moderate type lesions, and of the 20 cells in group IV (cell death), 18 had the most severe lesion type. The short term physiologioal effects upon coll contractility (up to 30 minutes post-irradiation) of selective mitochondrial deletion were determined. Up to 36 large mitochondria were destroyed with the least severe lesion type, and no change in cell contractility was observed. This contrasts with the repid cell death often obtained by destroying a single mitochondrion with the severe lesion type. The morphology and laser effects precipitating cell death are discussed. Quiesoent cells have been stimulated to contract by irradiation and a few have continued to contract up to 5 minutes post-irradiation. These results are disoussed in terms of the "pacemaker" cell theory.
\end{abstract}

\section{Introduction}

Preliminary observations have indicated that it is possible to alter individual mitochondria of myocardial oells in tissue culture by laser micro-irradiation (effective beam diameter, 0.25 to $1 \mu \mathrm{m}$ ). The reduced cytochromes $c$ and $c_{1}$ act as natural chromophores absorbing the blue-green laser light [7]. By selecting either mitochondria of light or dark optical phase density, or by varying the power of the laser, it was possible to produce mitochondrial lesions of specific morphology as 
viewed through the phase microscope [2]. The least severe lesion (type I) appeared as a slight phase darkened area at the site of irradiation within the mitochondrion; the lesion of moderate severity (type II) appeared as a darkened area with a light spot (hole?) in the center; the most severe lesion (type III) was the destruction of the entire organelle. The ability to produce such precise alterations within either a single or specific number of organelles, affords a unique opportunity to investigate myocardial cell function in vitro.

Though the morphological alterations were shown to be directly dependent upon either laser output or mitochondrial optical density, the contractile responses of the myocardial cells were varied and often difficult to interpret [2]. This was due, in part, to the fact that the irradiated cell was often one of a larger network of myocardial cells. It has been established $[4,5]$ that individual cell contractility can be greatly affected by adjacent contractile cells (i.e., as two cells contracting at different rates come into contact they often synchronize beat frequencies with the more rapid rate dominating). Laser-induced changes in cell contractility might be obscured or compromised by feedback from unirradiated adjacent contractile cells. A second source of difficulty in evaluating the contractile changes is understanding the nature of the cellular damage. Previous studies [2] have not attempted to delineate between primary cellular alterations resulting from functional removal of mitochondria, or secondary effects due to the absorption and dissipation of laser energy resulting in heating, acoustic shock, pressure waves, ionization, and free radical formation [6].

In this manuscript we will (i) describe the contractile responses of irradiated single isolated myocardial cells; (ii) correlate functional response with the type of mitochondrial lesion produced, (iii) distinguish between primary effects due to destruction of mitochondria, and secondary effects resulting from energy absorption and dissipation. In addition, observations on cell death and preliminary results of irradiation of non-contracting myocardial cells will be presented.

\section{Materials and Methods}

The laser microbeam system has been described in detail [1]. The beam of a high power pulsed argon laser $(488 \mathrm{~nm}, 514 \mathrm{~nm})$ is directed into a Zeiss photomicroscope where it is focused by a standard oil immersion objective (Zeiss neofluar, $\times 100$ ). The entire system is complexed with a closed circuit television and $16 \mathrm{~mm}$ timelapse movie camera. The image on the television monitor is parfocal with the focal plane of the microscope. When a cell is to be irradiated, it is placed on the microscope stage (in an appropriate culture chamber) and its image located on the television screen. The desired region of the cell (a single mitochondrion) is then moved under a cross-hair on the monitor that denotes the focal point of the laser. The laser is fired while the cell is visible on the television screen thus permitting continual viewing of the cell. The size of the focused laser spot is controlled by 
changing the angle of divergence of the beam prior to entry into the microscope. Effective beam diameters can be varied from 0.25 to $10 \mu \mathrm{m}$. A calibrated vacuum photodiode is used to monitor energy in the focused spot [1,3]. Energy densities are controlled by attenuating the laser beam with calibrated neutral density filters. The argon laser is a Hughes $3030 \mathrm{H}$, that has a maximum multiwavelength output of $12 \mathrm{~W}$ in single mode, and $35 \mathrm{~W}$ in multimode. The duration of a single pulse is $50 \mu 8$. Energy density in the focal spot in all experiments was between 50 and $200 \mu \mathrm{J}$. The effective focal spot was 1 to $2 \mu \mathrm{m}$.

Myocardial cells were established in Rose multipurpose eulture chambers according to the method of Mark \& Strasser [5]. Ventricles from 1 to 4 day old rats were cut into small pieces ( 1 to $2 \mathrm{~mm}^{2}$ ) and passed through the stepwise trypsinization procedures. Following resuspension in supplemented minimal essential medium [5] and adjustment of $\mathrm{pH}$ to 7.4 , the cells were injected into the culture chambers. After incubation at $37^{\circ} \mathrm{C}$ for 2 days, numerous beating myocardial cells were attached to the bottom glass plate of the chamber. With medium changes every 4 to 6 days, the cultures remained in good condition (cells contracting with a regular periodicity) for 2 to 3 weeks.

Irradiation of cells was accomplished by placing one of the chambers on the microscope stage as described above. A constant air curtain incubator at $37^{\circ} \mathrm{C}$ was continually directed at the chambers on the microscope stage. In all the experiments described in this manuscript myocardial cells were chosen for irradiation only if they were not in contact with other contracting cells. If there were nonmyocardial cells in contact with the target cell, it was also ascertained that no other contracting myocardial cells were in contact with these. This was to insure that changes in target cell contractility were not affected by other non-irradiated, contracting myocardial cells. This phenomenon does occur, and will be the subject of another study. The beat frequency (contractions/min) of the target cell was established prior to irradiation, $3 \mathrm{~min}$ and $30 \mathrm{~min}$ following irradiation. Notations were also made with respect to cell death, cessation of contraction, regularity of contraction, and whether or not the cell exhibited rapid, irregular, contractions (fibrillation). In all experiments except those designed to delineate primary from secondary effects, only one mitochondrion was irradiated. The mitochondrion was categorized prior to irradiation with respect to size (small $<1 \mu \mathrm{m}$ in diameter; medium, 1 to $2 \mu \mathrm{m}$; and large, $>2 \mu \mathrm{m}$ ) and optical phase density (light or dark). Each mitochondrion was scored by two separate individuals. Mitochondria of a spherical nature were always chosen. Following irradiation the lesion was categorized as type I, II, or III ([2]; see also section 1 of this paper). Since preliminary studies [2] had indicated that the position of the irradiated mitochondrion with respect to the cell nucleus was important, a series of irradiations involving mitochondria near and distant from the nucleus was undertaken. Experiments involving irradiation of non-mitochondrial cytoplasm have already indicated that the mitochondria are the sites of laser energy absorption $[2,7]$. 


\section{Results}

The observed sequences of contractile changes have been divided into four major groups : I, no change; II, change followed by a return to rhythmic contraction; III, cessation of contraction; IV, cell death. Groups II, III and IV have been subdivided into subgroups ( $\mathrm{A}$ to $\mathrm{K}$, Table 1 ). A total of eleven different contractile responses were observed following laser micro-irradiation. Observations were made at 0,3 and $30 \mathrm{~min}$ following irradiation. Data on pre- and post-irradiation beat frequencies are presented in Table 2 . The change in beat frequency is expressed as a raw change in beats/min and as a percentage of theinitial contraction rate [changein(beats/min)/ (initial beats/min)]. For the purpose of comparing the different major groups to the

TABLE 1. Functional sequences

\begin{tabular}{|c|c|c|c|c|c|c|}
\hline \multirow[b]{2}{*}{ Group } & \multirow[b]{2}{*}{ Definition } & \multirow[b]{2}{*}{ Subgroup } & \multicolumn{3}{|c|}{ Time from irradiation (min) } & \multirow{2}{*}{$\begin{array}{l}\text { No. } \\
\text { cell }\end{array}$} \\
\hline & & & $0^{*}$ & 3 & 30 & \\
\hline I & No change & - & 一 & - & - & 14 \\
\hline \multirow[t]{6}{*}{ II } & Change followed by & A & Stop & Fibrillation & Rhythmic & 9 \\
\hline & return to rhythmic & $\mathbf{B}$ & Fibrillation & Rhythmic & - & 5 \\
\hline & contraction & $\mathrm{C}$ & Stop & $\begin{array}{l}\text { Irregular } \\
\quad \text { contractions }\end{array}$ & Rhythmic & 1 \\
\hline & & $\mathbf{D}$ & Stop & Rhythmic & - & 1 \\
\hline & & $\mathbf{E}$ & Irregular & Rhythmic & - & 1 \\
\hline & & $\mathbf{F}$ & No effect & Irregular & Rhythmic & 1 \\
\hline \multirow[t]{2}{*}{ III } & Stops contractions & $\mathrm{G}$ & Fibrillation & Stop & - & 2 \\
\hline & & $\mathbf{H}$ & Stop & Fibrillation & Stop & 2 \\
\hline \multirow[t]{3}{*}{ IV } & Death & I & Death & - & - & 14 \\
\hline & & $\mathbf{J}$ & Stop & Death & - & 4 \\
\hline & & K & Fibrillation & Death & - & 2 \\
\hline
\end{tabular}

* Time 0 was immediately after irradiation.

control population of cells, the per cent beat change was used. This was necessary because cells with high initial beat rates often had higher raw beat changes than the slower contracting cells, yet the per cent change might be the same or less (e.g. cells no. 2 and no. 11, group I). In fact, when the percentage beat change is plotted against the initial beat rate (Figure 1), a negative correlation is noted. This suggests that cells with slower initial beat frequencies tend to have agreater percentage change than cells with the higher initial beat rates. These observations illustrate the importance of (i) selecting a random sample of cells, and (ii) choosing populations (groups) of cells that have similar distributions of beat frequencies. In these experiments cells were chosen for irradiation by scanning through the culture chamber and irradiating every contracting "single" (not attached to another cell) cell. To determine that the the various groups of pre-irradiation cells were from similar populations a $t$-test was performed on the means of the pre-irradiation beat frequencies of the different 
LASER IRRADIATION OF MTTOCHONDRIA

TABLE 2. Beat frequency data

\begin{tabular}{|c|c|c|c|c|c|}
\hline Group & Cell no. & $\begin{array}{l}\text { Pre-irradiation } \\
\text { beat frequency } \\
\text { (beats } / \mathrm{min} \text { ) }\end{array}$ & $\begin{array}{l}\text { Post-irradiation* } \\
\text { beat frequency } \\
\text { (30 min) }\end{array}$ & $\begin{array}{c}\text { Change } \\
\text { (beats/min) }\end{array}$ & $\begin{array}{c}\text { Change } \dagger \\
(\%)\end{array}$ \\
\hline \multirow[t]{14}{*}{ I } & 1 & 84 & 84 & 0 & 0 \\
\hline & 2 & 66 & 78 & +12 & +18.2 \\
\hline & 3 & 72 & 60 & -12 & -16.7 \\
\hline & 4 & 90 & 90 & 0 & 0 \\
\hline & 5 & 72 & 72 & 0 & 0 \\
\hline & 6 & 60 & 60 & 0 & 0 \\
\hline & 7 & 60 & 60 & 0 & 0 \\
\hline & 8 & 120 & 120 & 0 & 0 \\
\hline & 9 & 132 & 138 & +6 & 4.5 \\
\hline & 10 & 150 & 150 & 0 & 0 \\
\hline & 11 & 198 & 168 & -20 & -10.1 \\
\hline & 12 & 132 & 126 & -6 & -4.5 \\
\hline & 13 & 48 & 60 & +18 & +37.5 \\
\hline & 14 & 150 & 210 & +60 & +40 \\
\hline \multicolumn{6}{|l|}{ II } \\
\hline \multicolumn{6}{|c|}{ Subgroup } \\
\hline \multirow[t]{9}{*}{$A$} & 15 & 76 & 72 & -4 & -5.3 \\
\hline & 16 & 104 & 104 & 0 & 0 \\
\hline & 17 & 72 & 84 & +12 & +16.7 \\
\hline & 18 & 162 & 162 & 0 & 0 \\
\hline & 19 & 168 & 162 & -6 & -3.6 \\
\hline & 20 & 72 & 60 & -12 & -16.7 \\
\hline & 21 & 72 & 66 & -6 & -8.3 \\
\hline & 22 & 96 & 90 & -6 & -6.3 \\
\hline & 23 & 202 & 168 & -34 & -16.8 \\
\hline \multirow[t]{5}{*}{$\mathbf{B}$} & 24 & 36 & 36 & 0 & 0 \\
\hline & 25 & 36 & 36 & 0 & 0 \\
\hline & 26 & 60 & 56 & -4 & -6.7 \\
\hline & 27 & 132 & 156 & +24 & +18.2 \\
\hline & 28 & 96 & 96 & 0 & 0 \\
\hline C & 29 & 156 & 144 & -12 & -7.7 \\
\hline $\mathrm{D}$ & 30 & 60 & 72 & +12 & +20.0 \\
\hline $\mathbf{E}$ & 31 & 72 & 72 & 0 & 0 \\
\hline $\mathbf{F}$ & 32 & 78 & 90 & +12 & +15.4 \\
\hline \multicolumn{6}{|l|}{ III } \\
\hline \multicolumn{6}{|c|}{ Subgroup } \\
\hline \multirow[t]{2}{*}{ G } & 33 & 126 & 0 & -126 & -100 \\
\hline & 34 & 120 & 0 & -120 & -100 \\
\hline \multirow[t]{2}{*}{$\mathbf{H}$} & 35 & 156 & 0 & -156 & -100 \\
\hline & 36 & 156 & 0 & -156 & -100 \\
\hline \multicolumn{6}{|l|}{ IV } \\
\hline \multicolumn{6}{|c|}{ Subgroup } \\
\hline I & $37-50$ & - & Death & - & -100 \\
\hline $\mathrm{J}$ & $51-54$ & - & Death & - & -100 \\
\hline K & $55-56$ & - & Death & - & -100 \\
\hline
\end{tabular}


TABLE 2-continued

\begin{tabular}{|c|c|c|c|c|c|}
\hline Group & Cell no. & $\begin{array}{c}\text { Pre-irradiation } \\
\text { beat frequency } \\
\text { (beats/min) }\end{array}$ & $\begin{array}{l}\text { ost-irradiation* } \\
\text { eat frequency } \\
\text { (30 min) }\end{array}$ & $\begin{array}{c}\text { Change } \\
\text { (beats/min) }\end{array}$ & $\begin{array}{c}\text { Change } \dagger \\
(\%)\end{array}$ \\
\hline Control & $\begin{array}{l}57 \\
58 \\
59 \\
60 \\
61 \\
62 \\
63 \\
64 \\
65 \\
66 \\
67 \\
68 \\
69 \\
70 \\
71 \\
72 \\
73\end{array}$ & $\begin{array}{r}60 \\
60 \\
24 \\
60 \\
32 \\
96 \\
62 \\
76 \\
80 \\
112 \\
56 \\
68 \\
112 \\
136 \\
80 \\
120 \\
64\end{array}$ & $\begin{array}{r}60 \\
64 \\
20 \\
60 \\
40 \\
120 \\
88 \\
60 \\
64 \\
104 \\
48 \\
72 \\
116 \\
124 \\
68 \\
128 \\
64\end{array}$ & $\begin{array}{r}0 \\
+4 \\
-4 \\
0 \\
+8 \\
+24 \\
+26 \\
-16 \\
-16 \\
-8 \\
-8 \\
+4 \\
+4 \\
-12 \\
-12 \\
+8 \\
0\end{array}$ & $\begin{array}{c}0 \\
+6.7 \\
-16.7 \\
0 \\
+25 \\
+25 \\
+41.9 \\
-21.1 \\
-20.0 \\
-7.1 \\
-14.3 \\
+5.9 \\
+3.6 \\
-8.8 \\
-15.0 \\
+6.7 \\
0\end{array}$ \\
\hline
\end{tabular}

* The post-irradiation beat frequencies given for the control group are the beat rates $30 \mathrm{~min}$ after the initial rates were taken; the control group was not subjected to irradiation.

$\dagger$ Raw change (beats/min)/pre-irradiation rate.

groups. A comparison of groups I and II to each other and to the control group indicates that it is valid to compare these groups with respect to beat frequency changes (Table 3). In group I pre-irradiation contraction rates varied from 60 beats/min (cells no. 6 and no. 7) to 198 beats/min (cell no. 11). None of the 14 cells in this group appeared to exhibit contractility changes at the time of irradiation or up to $30 \mathrm{~min}$ post-irradiation. A comparison of the $\bar{x} \%$ change between group I and the control group indicates that both groups are similar (Table 4). The postirradiation variation in beat frequencies of group I do not appear to be different from the normal variations observed in the unirradiated cells. Cytological alterations, other than damage to the irradiated mitochondrion, were not detected with the phase microscope.

In group II (change in beat frequency followed by a return to rhythmic contraction) six different sequences were observed (subgroups A to F, Table 1). Nine of the 18 cells in this group were in subgroup A: cessation of contraction at time of irradiation, fibrillation by 3 min post-irradiation, and a return to rhythmic contraction by $30 \mathrm{~min}$ post-irradiation. The fibrillation was characterized by rapid, irregular contractions. Numerous unco-ordinated regions of contraction often were observed within the irradiated cell cytoplasm. In all of the nine cells observed, fibrillation appeared to decrease with time (the fibrillation became less "violent"). 


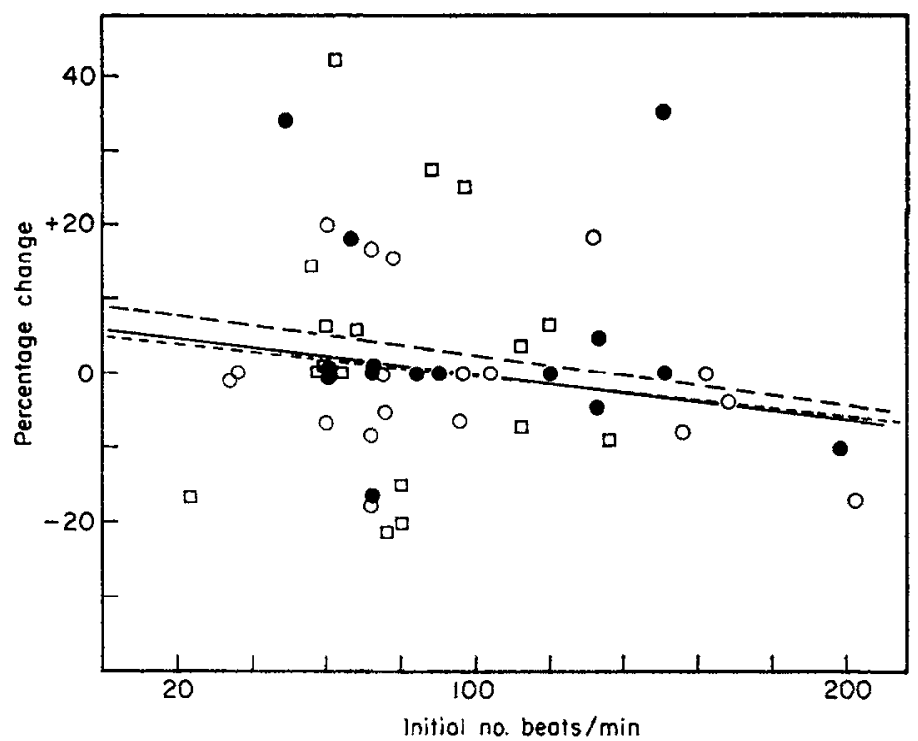

FIGURE 1. Initial beats/min plotted against percentage chenge in beat frequency. $\square---\square$, Control (correlation coefficient $=-0.112$ ); $---O$, group I (correlation coefficient $=0.284$ ); $\mathrm{O}-\mathrm{O}$, group II (correlation coefficient $=-0.258$ ).

The second most frequent sequence of events in group II cells was an immediate fibrillation followed by a return to rhythmic contraction (subgroup B). Five cells were observed in this category. The events of fibrillation and the return to normal

TABLE 3. Pre-irradiation beat frequency (beats/min)

\begin{tabular}{|c|c|c|c|c|}
\hline & $\begin{array}{c}\text { Beat rate, } \\
\bar{x}\end{array}$ & $\sigma$ & $t^{*}$ & $n$ \\
\hline Control & 77 & 29.6 & - & - \\
\hline Group I & 102 & 44.7 & 1.93 & 31 \\
\hline Group II & 97 & 47.6 & 1.53 & 35 \\
\hline
\end{tabular}

* These $t$ values indicate that groups I and II are not statistically different from the control at $95 \%$ confidence limits.

TABLE 4. Change in beat frequency

\begin{tabular}{lrrrr}
\hline & $\bar{x} \% *$ change & \multicolumn{1}{c}{$\sigma$} & $t \dagger$ & $n$ \\
\hline Control & 13.6 & 11.4 & - & - \\
Group I & 9.4 & 7.5 & 1.0 & 31 \\
Group II & 7.9 & 7.5 & 1.78 & 35 \\
\hline
\end{tabular}

* \% Change $=$ raw change/initial rate.

$\dagger$ These $t$ values indicate that groups I and II are not statistically different from the control at $95 \%$ confidence limits. 
contractility are similar to those discussed for the preceding sequence. The four remaining sequences in group II (sequences $\mathrm{C}$ to $\mathrm{F}$ ) were observed less frequently. Sequences $\mathrm{C}$ and $\mathrm{D}$ involved cells that stopped contracting at the time of irradiation, and then either started contracting irregularly (sequence $\mathrm{C}$ ), or at a rhythmic rate (sequence D) by 3 minutes. At 30 min post-irradiation cells in both groups were contracting rhythmically. Sequence E involved cells that started contracting irregularly immediately following irradiation, and returned to a rhythmic rate by 3 min. The final sequence in group II (sequence F) was a cell that did not appear immediately to be affected by the irradiation, but that did contract irregularly by 3 min post-irradiation, and returned to a more rhythmic rate by $30 \mathrm{~min}$. In summary, all of the cells in group II exhibited a change in contractility either at the time of irradiation, or by $3 \mathrm{~min}$ post-irradiation. By $30 \mathrm{~min}$ post-irradiation all cells had returned to a normal, rhythmic contraction rate.

Cells that were not killed, but stopped contracting as a result of the irradiation, were placed in group III. Two cells (nos 33 and 34) started fibrillating immediately upon irradiation, and by 30 min all contractile activity had ceased (subgroup G). The other two cells in this group (cells no. 35 and no. 36 , sequence $H$ ) appeared to stop contracting at the time of irradiation, by $3 \mathrm{~min}$ post-irradiation were observed in rapid fibrillation, and by $30 \mathrm{~min}$ had ceased all contractile activity. Cytological indications of cell death were not evident in any of these four cells.

All those cells that died immediately or within $30 \mathrm{~min}$ of irradiation were placed in group IV. Of the 20 cells in this group, 14 exhibited the cytological features of death (nuclear and cytoplasmic pycnosis, cytoplasmic vacuolation, membrane blebbing, darkening of nuclear membrane) within a few seconds of irradiation (sub group I). Four cells (subgroup J) stopped contracting upon irradiation and by 30 min were dead; two cells (subgroup K) started fibrillating upon irradiation, and were dead by 30 min post-irradiation.

\section{Lesion morphology and functional response}

An attempt was made to correlate lesion type with contractile response. The data are summarized in Table 5. Of the 14 cells in group I (no contractility changes), eight had type I lesions (least severe), and six had type II lesions (moderate). This was the only group with type I lesions. Cells in the group II (return to rhythmic contraction) had a predominance of type II lesions (16/18) and two exhibited type III lesions. All four cells in group III (cessation of contraction) had type II lesions. The large majority of cells that died (group IV) had type III lesions (18/20). Only two of those cells had mitochondrial lesions of the moderate type (II). It is evident that a correlation does exist between increasing severity of the lesion and the functional responses. However, it should be pointed out that a type III lesion does not necessarily result in cell death. Two cells returned to a normal contractile rate despite the production of a type III lesion. 
PLATE 1. Rat myocardial cell prior to micro-irradiation : arrow indicates the mitochondrion that will be irradiated. $\times 1875$.

PLATE 2. Five seconds post-irradiation: note damaged mitochondrion (arrow), slight granulation to nucleoplasm, and damage to nuclear membrane. $\times 1875$.

PLATE 3. One minute post-irradiation: note numerous vacuoles in eytoplasm (small arrows), dark nuclear membrane, condensed mitochondria in cytoplasm. $\times 1875$. 

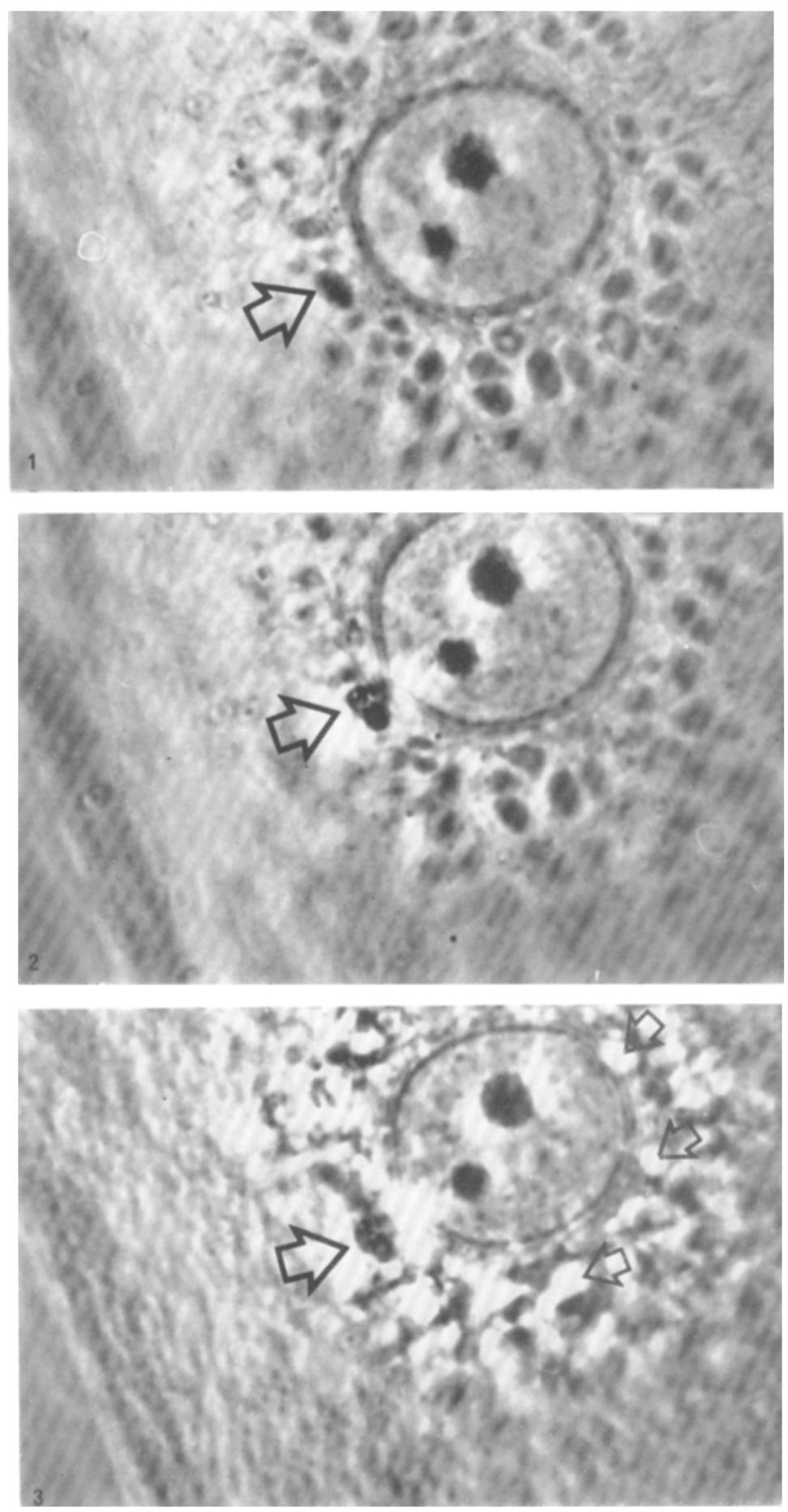
TABLE 5. Functional response and lesion type

\begin{tabular}{|c|c|c|c|c|}
\hline & \multicolumn{3}{|c|}{ Lesion type } & \multirow[b]{2}{*}{ Totals } \\
\hline & $\begin{array}{c}\text { Weak } \\
\text { I }\end{array}$ & $\begin{array}{c}\text { Moderate } \\
\text { II }\end{array}$ & $\begin{array}{c}\text { Severe } \\
\text { III }\end{array}$ & \\
\hline No change-group I & 8 & 6 & 0 & 14 \\
\hline Return to rhythmic - group II & 0 & 16 & 2 & 18 \\
\hline Stop-group III & 0 & 4 & 0 & 4 \\
\hline Death-group IV & 0 & 2 & 18 & 20 \\
\hline Totals & 8 & 28 & 20 & \\
\hline
\end{tabular}

\section{Secondary versus primary damage}

In an effort to distinguish between the primary physiological effects resulting from removal of mitochondria from the cell, and the secondary effects due to laser energy dissipation within the cell, a large number of mitochondria in the same cell were irradiated with minimal laser energies capable of producing only type I lesions, and marginal type II lesions (on the borderline between type I and II). As indicated in a previous section and elsewhere [2], the type I lesion appears to result in the most localized, least traumatic type of cytoplasmic alteration. Damage appears to involve the entire irradiated mitochondrion. In all the cells with type I lesions on a single mitochondrion, no contractile changes were observed (Table 5). Similarly, when many mitochondria in the same cell were irradiated, no change in contractility was noted. This experiment was repeated three times. In one cell, 36 mitochondria ranging in size from 0.5 to $4 \mu \mathrm{m}$ were altered with type I lesions. The pre- and post-irradiation beat frequencies were 32 beats $/ \mathrm{min}$. Tho other two cells had a total of 19 and 12 mitochondria altered. Pre- and post-irradiation contractile rates were 72 to 64 , and 64 (unchanged), respectively. It would appear that in all three cells, the destruction of a substantial number of the large mitochondria was possible without affecting cell contractility (within a $30 \mathrm{~min}$ period following the last irradiation). This contrasts with the destruction of a single mitochondrion with a type III lesion (with a higher laser energy) usually resulting in cell death. In this situation, the production of heat, or some other less common physical phenomenon [6] might be considerable and rosult in more general cytoplasmic effects, eventually culminating in cell death.

\section{Cell death}

Cell death may be rapid (within a few seconds of irradiation) or it may occur more gradually over several minutes. In addition, it may be prcceded by a cessation of contraction, or fibrillation. Regardless of the time sequence involved, the cytological features of the dead (or dying) cell are obvious. A typical sequential pattern of cell death is illustrated in Plates 1 to 3 . The cell prior to irradiation (Plate 1) has a grayish nuclear membrane and nucleoplasm. Most of the mito- 
chondria are spherical and of a uniform density. Large cytoplasmic vacuoles are not evident. Immediately following irradiation (within $5 \mathrm{~s}$ ) the altered mitochondrion appears to have a much darker optical phase density (coagulation?) as well as a fragmented appearance (Plate 2; this is a type III lcsion). The nuclear membrane also appears to be darker, and the nucleoplasm is more granular appearing. Large cytoplasmic vacuoles are not yet evident. By 1 min post-irradiation the nuclear membrane has become darker and more compact (Plate 3). The cytoplasm now contains many large vacuoles, and the non-irradiated mitochondria appear darker and more condensed. It is also of particular interest to note that the area of nuclear membrane closest to the irradiated mitochondrion appears to be affected (Plates 2 and 3). The extent to which this contributes to cell death is not known. To further elucidate this phenomenon, mitochondria were irradiated at varying distances from the nucleus and the occurrence of cell death noted. Lesions

TABLE 6. Cell death and mitochondrial location

\begin{tabular}{|c|c|c|c|}
\hline & \multicolumn{3}{|c|}{$\begin{array}{c}\text { Mitochondrial position in } \\
\text { cytoplasm with respect to } \\
\text { nucleus }\end{array}$} \\
\hline & Close & Middle & Distant \\
\hline Death & 7 & 14 & 13 \\
\hline Survive & 4 & 6 & 9 \\
\hline$\%$ Death & 64 & 70 & 59 \\
\hline
\end{tabular}

were all of type II and III. The position of the mitochondrion with respect to the nucleus is denoted as "close" (within $2 \mu \mathrm{m}$ ), "middle" (5 to $10 \mu \mathrm{m}$ ), and "distant" $(15$ to $30 \mu \mathrm{m}$ ). The data arc summarized in Table 6. There does not appear to be a relationship between the position of the mitochondrion to the nucleus with respect to the frequency of cell death. This does not preclude the fact that nuclear membrane damage does contribute in some way to cell death.

\section{Quiescent cell irradiation}

In the course of conducting the above experiments it was frequently observed that when non-contracting myocardial cells were irradiated, contraction was initiated. Cells chosen for this type of irradiation were determined to be non-contracting by observation for $1 \mathrm{~min}$ prior to irradiation. All cells chosen for irradiation had numerous large, dark mitochondria. Of 22 quiescent cells irradiated, 10 initiated contraction following irradiation. A detailed analysis on the lesion types, duration and character of the contractions has not been conducted. Several of these cells have been observed still contracting 5 min following irradiation. 


\section{Discussion}

Several consistent patterns of cell behaviour are evident. Of the 22 cells that demonstrated initial alteration in contractility and that did not die (groups II, III), 18 returned to rhythmic contractions. In 14 of these cells the return to rhythmic contractility was preceded by rapid "fibrillation". The ability of the cells to return to a normal rhythmic contraction following this violent fibrillation is interesting considering the role of this phenomenon in general heart function. In addition to the return to a rhythmic contraction rate the data also suggest that the altered cells return to a beat frequency similar to the pre-irradiation rate (Table 4). The mean per cent change for group II, $7.9 \%$ is less than the mean for the control, $13.6 \%$. A comparison of these means with the $t$-test indicates that they are not significantly different ( $95 \%$ confidence limits). Six of the 18 cells in group II returned to exactly the same pre-irradiation beat frequency. These data imply that there is some intrinsic cellular property (or properties) that establishes an inherent beat rate as well as general contractile periodicity. The fact that the single cell can be manipulated to predictably undergo contractile changes and recovery, should permit elucidation of the mechanisms involved in the establishment of beat frequency and general cell contractility. The determination of a negative correlation between initial beat frequency and the percentage change (Figure 1) also is suggestive of some basic underlying mechanism.

It would appear that a correlation can also be made between the severity of the lesion and the type of functional response observed. The least severe lesion type (I) was only found in the group of cells that were not functionally affected by the irradiation (group I). Only six cells in this group had type II (moderate) lesions, and none had the severe type of alteration (type III). At the other end of the spectrum, 18 of the 20 cells were killed with severe lesions (type III), while none died with type I lesions. The great majority of cells that were not killed by the irradiation, yet were functionally altered, had lesions of moderate severity. Since we have already demonstrated a correlation between lesion type, mitochondrial phase density, and laser output [2], it would appear that we could extend our functional correlations to these parameters. Furthermore, it appears that in those cases where a functional alteration is precipitated (contractile change, or death), it results from a secondary effect of radiation ubsurption rather than the mere deprivation of mitochondria from the cell. This is suggested by the fact that destruction of numerous mitochondria with relatively low laser outputs (resulting in mostly type I lesions) did not result in any detectable alteration in cell contractility, whereas destruction of a single mitochondrion with a relatively high laser output often resulted in cell death and a tiype IIT lesion.

The observations on cell death indicate a definite sequential pattern of events, beginning with a rather severe type of morphological alteration. The rapidity with which many of the cells die following mituchondrial irradiation (within a few minutes) would suggest that the immediate cause of death is related to the dissipa- 
tion of the laser energy. Though the exact nature of the damage is not known, such phenomena as localized heating, acoustic shock, electric field effects, photochemical effects, or ionization [5] could be operating. These effects could precipitate extensive damage within the cytoplasm, nucleus, or cell membranes. In those cells where cell death is more gradual (over $20 \mathrm{~min}$ ) it is possible that the gross damage to the cytoplasm or membranes is less severe, and that the cell is undergoing a more gradual lysis that may be due to localized lysosomal damage or the release of toxic products from the irradiated mitochondrion.

The suggestion in a previous publication [2] that the position of the irradiated mitochondrion with respect to the nucleus is an important factor in determining whether or not a cell is killed by the irradiation, does not at first glance appear to be valid. However, if cell death is being caused by cytoplasmic and membrane damage due to a thermal effect (or some other effect) radiating out from the site of onergy absorption (the mitochondrion), then it is possible that in the case of the mitochondria near the nucleus, nuclear damage as well as cell membrane damage is causing cell death. If one considers the geometry of the tissue culture cell growing on a thin coverglass, it is possible to envisage a situation where nuclear damage is the sole cause of cell death. When the cell flattens out on a glass surface, the total cell thickness is greatest in the region of the nucleus, and decreases towards the periphery [8]. The irradiation of a mitochondrion near the nucleus that is approximately equidistant from the upper and lower (with respect to the glass surface) cell membranes, might result in considerable thermal damage to the nucleus and only minimal damage to the outer cell membranes. However, irradiation of a mitochondrion in the periphery of the cell cytoplasm (where the total cell thickness is small when compared to the thickness in the area of the nucleus) could result in considerable thermally-induced membrane damage. Thus the percentage cell death due to irradiation of a mitochondrion close to the nucleus and one located peripherally might approach similar values, as indicated in Table 6.

The preliminary observation of stimulating non-contracting myocardial cells to beat rhythmically is one of those unexpected yet interesting findings. The frequency with which this phenomenon occurs attests to its non-artifactual nature. According to De Haan [4] a quiescent cell is either (i) a non-pacemaker (a contractile cell which does not initiate its own electrical impulse under the prevailing conditions), (ii) a "covert" pacemaker (a cell which has an electrically active pacemaker membrane, but which cannot respond to its own stimuli because of contractile elements and excitation-contraction coupling system deficiencies), or (iii) a noncontracting fibroblastic or endothelial cell. Since we are irradiating only myocardial cells with the typical numerous large mitochondria, possibility (iii) above is eliminated. This means that those quiescent cells that are stimulated to contract are either non-pacemaker cells whose "prevailing conditions" have in some way been altered to permit initiation of an electrical impulse [situation (i), above], or they are "covert" pacemaker cells that have had their contractile elements or excitation- 
contraction systems affected so that they are now capable of responding to their own stimuli.

In this manuscript we have presented data correlating contractility changes and cell death with laser-induced morphological changes in heart cell mitochondria. We have established that under a given set of parameters (laser, mitochondrial, cytological) fairly discrete functional responses can be elicited. The real nature of these responses (fibrillation, cell death, contractility changes) and the extent to which they reflect the in situ situation remain to be determined. The ability to selectively manipulate myocardial cells by laser micro-irradiation in conjunction with the already established techniques of electrophysiology, biochemistry, and electron microscopy, should permit elucidation of the basic cellular mechanisms involved in these functional responses and contribute considerably to our understanding of heart cell function.

\section{Acknowledgements}

This research has been supported by grants: PHS-HE 13750-01; University of Michigan Phoenix Memorial Grant; University of Michigan Rackham Research Grant; NSF Grant GB 24457; and an equipment grant from the University of Michigan Institute for Science and Technology.

\section{REFERENCES}

1. Berns, M. W. A simple and versatile argon laser mierobeam. Experimental Cell Research 65, 470-473 (1971).

2. Berns, M. W., Gamaleja, N., Olson, R., Dutry, C. \& Rounds, D. E. Argon lager microirradiation of mitochondria in rat myocardial cells in tissue culture. Joumal of Cell Physiology 76, 207-214 (1970).

3. Berns, M. W., Chena, W. K., Floyd, A. D. \& OHNUki, Y. Chromosome lesions produced with an argon laser microbeam without dye sensitization. Science, New York 171, 903-905 (1971).

4. De HaAN, R. L. Spontaneous activity of cultured heart cells. In Factors Influencing Myocardial Contractility. (R. Tanz, F. Kavaler \& J. Roberts, Eds.) pp. 217-230. Academic Press, New York (1967).

5. Mark, G. \& Strasser, F. Pacemaker activity and mitosis in cultures of newborn rat ventricle cells. Experimental Cell Research 44, 217-233 (1966).

6. Moreno, G., LUTZ, M. \& Bessis, M. Partial cell irradiation by ultraviolet and visible light: conventional and laser sources. Intermational Review of Experimental Pathology 7, 99-137 (1969).

7. Rounds, D. E., Orson, R. S. \& Jounson, F. M. The effect of the laser on cellular respiration. Zeitschrift für Zellforschung und mitroskopische Anatomie 87, 193-198 (1968).

8. Trinkaus, J. P. Cells Into Organs, p. 237. Prentice-Hall, Englewood Cliffs, N.J. (1969). 